\title{
O colégio universitário da UFMA no contexto das reformas educacionais (1968-2018)
}

\author{
Ufma's university school in the context of educational reforms \\ (1968-2018)
}

\section{El colegio universitario de ufma en el contexto de las reformas educacionales (1968-2018)}

\author{
Samuel Luis Velázquez Castellanos \\ iD $h t t p: / / o r c i d . o r g / 0000-0003-0849-348 X$ \\ Wilson Raimundo de Oliveira \\ http://orcid.org/0000-0001-6165-2924
}

\begin{abstract}
Resumo: Investiga-se a trajetória do ensino médio no Colégio Universitário da Universidade Federal do Maranhão (1968-2018) no intuito de avaliar sua inserção no contexto das reformas educacionais que trouxeram implicações para o currículo, problematizando-se sua identidade institucional desde sua origem no cenário de criação da própria Universidade em 1966. Analisa-se a trajetória do Colégio relacionando-a com as políticas educacionais para o ensino médio, ao focalizar-se nas disciplinas Filosofia, Sociologia, História e Geografia e, no debate em torno da Base Nacional Comum Curricular (2018), que Ihes retira o estatuto de disciplina escolar ao denominá-las de "práticas e estudos" e as dilui no itinerário formativo das "ciências humanas e sociais aplicadas". Utiliza-se como pressuposto teórico-metodológico a história cultural e faz-se uso da pesquisa bibliográfica e documental, auxiliando-nos de categorias norteadoras como a cultura escolar, culturas escolares, capital cultural e disciplinas escolares, assim como da historiografia educacional maranhense, para situar nosso objeto em discussão; lugar onde se percebe um panorama histórico de resistência daqueles que têm lutado por um ensino médio unificado, com currículo abrangente e voltado para a formação integral. Palvavras-chave: Ginásios e Colégios de Aplicação. Colégio Universitário. Cultura Escolar. Ensino Médio. Maranhão.
\end{abstract}

Abstract: The trajectory of high school is investigated at the University School of the Federal University of Maranhão (1968-2018), in order to evaluate its insertion in the context of the educational reforms that had implications for the curriculum, questioning its institutional identity since its origin in Brazil setting of the University itself in 1966. It analyzes the trajectory of this School relating it to the educational policies for high school, focusing on the subjects Philosophy, Sociology, History and Geography and, in the debate around the National Base Common Curriculum (2018), which removes the status of school discipline by calling them "practices and studies" and dilutes them in the formative itinerary of "applied human and social sciences". The theoretical-methodological assumption is the cultural history and makes use of bibliographical and documentary 
research, helping us from guiding categories such as the school culture, school cultures, cultural capital and school subjects, as well as Maranhão educational historiography, to situate our object under discussion; This is a place where we can see a historical panorama of resistance of those who have struggled for a unified high school, with a comprehensive curriculum focused on integral formation.

Keywords: Application Gymnasiums and Schools. University School. School culture. High school. Maranhão.

Resumen: Se investiga el trayecto de la preparatoria en el Colegio Universitario de la Universidad Federal de Maranhão (1968-2018) con el objetivo de evaluar su inserción en el contexto de las reformas educacionales que hicieron implicaciones para el currículo, problematizándose su identidade institucional desde su origen en el contexto de creacón de la propia Universidad en 1966. Se analisa el trayecto del Colegio relacionándolo con las políticas educacionales para la preparatoria, por enfocar en las asignaturas Filosofía, Sociología, Historia y Geografía y, en la conversación sobre la Base Nacional Común Curricular (2018), que les saca el estatuto de asignatura escolar al denominarlas de "prácticas y estúdios" y las disminuye en el trayecto formativo de las "ciencias humanas y sociales aplicadas". Se utiliza como conyectura teórico-metodológico la historia cultural y se utiliza la investigación bibliográfica y documental, ayudándonos en las categorias norteadoras como la cultura escolar, culturas escolares, capital cultural y asignaturas escolares escolares, bien como de la historiografia educacional maranhense, para situar nuestro objeto en cuestión; lugar donde se percibe un panorama histórcio de resistencia de aquellos que luchan por una preparatoria unificada, con currículo amplio para la formación integral.

Palabras-clave: Escuelas y Colegios de Aplicación. Colegio Universitario. Cultura Escolar. Preparatoria. Maranhão.

\section{INTRODUÇÃO}

No Brasil, os Colégios de Aplicação ${ }^{1}$ (antigos Ginásios) tiveram sua origem ligada ao movimento da escola nova. Os escolanovistas brasileiros, como Anísio Teixeira, Fernando de Azevedo, Lourenço Filho, entre outros, defendiam um novo modelo de educação pautado na centralidade do aluno e, portanto, no rompimento com os métodos tradicionais (MOVIMENTO DOS PIONEIROS DA EDUCAÇÃO NOVA, 1932). Estes educadores postulavam ainda a ampliação da educação obrigatória, de caráter laico e público. Em outras palavras, pretendiam trazer para a nação uma nova concepção de escola, seguindo teorias importadas da Europa e dos Estados Unidos, onde laboratórios de pesquisas educacionais

1 É importante destacar que já haviam sido implantadas instituições dessa natureza em períodos anteriores: as Escolas Modelos anexas às Escolas Normais, que funcionavam como espaço para o tirocínio das estudantes normalistas. No Maranhão, temos o exemplo da Escola Modelo Benedito Leite, criada em 1896, a partir da Lei $n^{\circ} 155$, destinando-se à formação pedagógica de meninos e meninas entre 6 e 12 anos de idade e como campo de estágio para as(os) alunas(os) da Escola Normal (CASTELLANOS, 2007; SILVA, 2017). Por outro lado, de acordo com Saldanha (2009, p.127), apesar de ter sido criada em 1896, a escola só foi inaugurada em 1900, "quando o governo do Estado (José Tomás de Porciúncula) pôde, enfim, equipá-la [...] Caracterizava-se [como] elitista, [...] [chegando] a ter aulas de francês e professores de piano. Seu curso, [a princípio] com duração de sete anos, [foi] reduzido a seis em 1906 [e em 1926, a 5 anos]" (SILVA, 2011). Com o surgimento, no âmbito da Reforma de Francisco Campos (1931) e de Gustavo Capanema (1942), dos primeiros cursos de formação de professores em Faculdades e Institutos de Ensino Superior, determinou-se às Faculdades de Filosofia Federais a obrigatoriedade de manterem "ginásios de aplicação" para a prática docente dos seus estudantes. Ginásios que, à medida que iam implantando também o segundo ciclo do ensino secundário, passaram a denominar-se "Colégios de Aplicação". 
difundiam novas orientações para a formação de professores. Por isso, esses intelectuais (que inclusive tinham influência sobre a legislação educacional brasileira) idealizaram os ginásios de aplicação, os quais foram criados pelo Decreto-Lei $n^{\circ}$ 9.053, de 12 de março de 1946, estabelecendo-se no seu artigo 1 $^{\circ}$, que: "as Faculdades de Filosofia Federais, reconhecidas ou autorizadas a funcionar no território nacional, fica[ria]m obrigadas a manter um ginásio de aplicação destinado à prática docente dos alunos matriculados no curso de didática" (BRASIL, 1946, p.520). Dessa forma, percebemos que a implantação dos Ginásios de Aplicação das Faculdades Federais de Filosofia, conforme previsto pelo referido Decreto-Lei, visava incrementar a formação de professores mais pragmáticos, dotados de uma nova mentalidade educacional e voltados ao cultivo de novas metodologias de ensino como defensores das ideias dos pensadores escolanovistas.

Neste mesmo espírito foi forjado o Decreto-Lei n ${ }^{\circ}$ 9.092, de 26 de março de 1946, no qual se exigia no artigo $4^{\circ}$, parágrafo $1^{\circ}$ que, "para [se] obter o diploma de licenciado, os alunos do quarto ano [receberiam] formação didática, teórica e prática, no ginásio de aplicação e [seriam] obrigados a um curso de psicologia aplicada à educação" (BRASIL, 1946, p. 548). A concepção pedagógica que orientou a criação desses ginásios, filiada ao pensamento escolanovista, apostava na instauração de centros de referência na formação de professores, principalmente para o ensino secundário, pois este vinha crescendo significativamente com a criação dos ginásios públicos e particulares e era necessário fortalecer as políticas voltadas para a preparação de professores que atuassem nesse nível de ensino. Esse crescimento estava relacionado com as medidas adotadas por Gustavo Capanema na reforma que concretizou como ministro da Educação e saúde no governo de Getúlio Vargas, na qual, organiza o sistema educacional brasileiro de forma que correspondesse com a divisão da sociedade em classes ou em categorias sociais, de modo que os níveis e modalidades do ensino (primário, secundário, superior, profissional ou feminino) fossem oferecidos de acordo com o papel que se esperava de cada uma dessas classes ou categorias (SCHWARTZMAN; BOMENY; COSTA, 2001).

Aos que concluíssem o ensino primário na reforma Capanema Ihes restavam as seguintes alternativas: o ingresso no ensino secundário, controlado por exigentes critérios de qualificação ou a matrícula em algum estabelecimento de ensino médio profissionalizante: aos primeiros, Ihes estava reservado o ensino superior; aos últimos se Ihes oferecia uma preparação para o trabalho nos setores agrícola, industrial, comercial etc. Como parte da qualificação exigida para o secundário, existiam os exames de admissão para os alunos e, a formação de professores diplomados em cursos de licenciatura, que geralmente ocorria nas Faculdades de Filosofia, Ciências e Letras das Universidades Federais. Nessa lógica, a ideia dos ginásios de aplicação ligados a essas faculdades vinha ao encontro do projeto dos "pioneiros da educação nova" de investir na formação de professores, para que estes educadores fossem capazes de formar uma juventude com espírito crítico que compusesse a nova intelectualidade brasileira. 
Para alguns dos intelectuais ligados ao movimento da Escola Nova, a exemplo de Laerte Ramos de Carvalho, a multiplicação de ginásios oficiais e particulares colocava em risco a qualidade do ensino secundário, de tal forma que à sua queda

[...] vinculava-se visceralmente a sua expansão, [ao criar-se] um número de vagas para o quadro do magistério secundário que excedia a capacidade do Estado de fornecer pessoal qualificado, leia-se formado pelas Faculdades de Filosofia, Ciências e Letras "ou equivalentes". O resultado era "o aproveitamento de pessoal sem nenhuma qualificação para os exercícios docentes" (OESP, 17/08/1947), ato daninho, haja vista que "o problema fundamental do ensino secundário, não nos cansamos de repeti-lo, é o da formação e recrutamento de nosso professorado" (OESP, 10/04/1948). (BONTEMPI JÚNIOR, 2006, p.145).

Por trás dessa preocupação, escondia-se a intenção de reservar a uma elite cultural o acesso ao ensino superior e, com isso, preparar quadros para assumir a direção política e econômica do país por meio do exercício de funções burocráticas nas instituições públicas e privadas. O surgimento dos ginásios de aplicação enquadra-se nessa conjuntura de dualidade que diferenciava a formação intelectual destinada aos que pretendiam entrar na universidade e a formação profissional concebida para os filhos dos trabalhadores. Tendência que se acentua na Lei 4.024, de 20 de dezembro de 1961, das diretrizes e bases da educação nacional, ao autorizar as universidades brasileiras a criarem outras modalidades escolares, a saber: o Colégio Universitário (propedêutico) e o Colégio Técnico Universitário (profissionalizante). Contexto em que a Fundação Universidade do Maranhão criou o Colégio Universitário, com a oferta do $3^{\circ}$ ano colegial, destinado a preparar seus alunos para 0 ingresso nos cursos superiores da instituição; transformando-o, a partir de 1972, em Colégio de Aplicação, dentro da perspectiva de reforma educacional que se delineava naquele momento histórico, onde novos métodos de ensino eram reclamados como condição para expandir o processo de escolarização nos níveis primário, secundário e superior.

A nosso ver, a trajetória do Colégio Universitário da UFMA destoa do perfil da maioria das instituições congêneres, sobretudo no que respeita ao momento histórico de sua consolidação (1980-2006), quando o seu público era constituído por famílias de baixa renda da periferia de São Luís (Vila Palmeira). Produz-se neste estabelecimento uma cultura escolar democrática que se projeta sobre o futuro da instituição, inventando-se uma identidade singular cuja continuidade podemos observar após a sua transferência para a cidade universitária em 2006. Com o intuito de destacar as implicações dessa cultura escolar específica para o currículo do ensino médio, focalizando-se as disciplinas de Filosofia, Sociologia, Geografia e História, as quais têm sido alvo das reformas educacionais deste nível de ensino nas últimas décadas, procuramos mostrar, neste trabalho, as formas de resistência deste Colégio no sentido de manter ou pelo menos lutar por um ensino médio unificado, com currículo abrangente que propicie formação mais ampla ou integral, mesmo diante das descontinuidades que têm marcado as reformas educacionais no Brasil. 


\section{PROCEDIMENTOS METODOLÓGICOS}

A história cultural como abordagem teórico-metodológica sustenta esta pesquisa, uma vez que "as relações econômicas e sociais não são anteriores às culturais, nem as determinam; elas próprias são campo de prática cultural e produção cultural" (HUNT, 1992, p. 9). Este entendimento permite conceber a realidade social do passado tal como ela é, construída pelas práticas, representações, apropriações, estratégias de poder e táticas de resistência presentes no campo de forças pelo qual se define o que é o real (BOURDIEU, 2007; CHARTIER, 1988; CERTEAU, 2012; BARROS, 2003; PESAVENTO, 2012). Nessa perspectiva, categorias como cultura escolar (JULIA, 2001; VIÑAO FRAGO, 2001); culturas escolares (FORQUIN, 1993), disciplina escolar (CHERVEL, 1990) e capital cultural (BOURDIEU, 2007), entre outras, se constituem em ferramentas teóricas para a garimpagem de dados e a análise documental no acervo do arquivo escolar; fontes cuja preservação garante acesso às materialidades textuais do passado e "[...] lentamente, vão dando vida às personagens, às tramas e, por fim, mancham de tinta folhas de papel em branco, tornando-se história." (CASTRO, 2017, p. 235).

Para este trabalho, foram selecionadas cinco pesquisas (quatro dissertações de mestrado e uma tese de doutorado), utilizando-se como critério o enquadramento das mesmas nos pressupostos teórico-metodológicos da História Cultural. Um aspecto comum entre elas é que dão conta de Colégios caracterizados pela elitização, que geralmente atendem alunos de bairros situados nas áreas mais estruturadas das seguintes cidades: Rio de Janeiro (MARTINS, 2015), Porto Alegre (LIMA, 2016), Aracaju (NUNES, 2008), Florianópolis (LUCIANO JÚNIOR, 2010), Recife (ALMEIDA, 2014). Nestes Colégios estudavam alunos pertencentes aos estratos sociais privilegiados intelectual e economicamente, que tinham acesso a bens culturais que os diferenciavam dos estudantes de outras escolas públicas e particulares. Em outras palavras, possuíam mais capital cultural nos seus três formatos: a) incorporado pelas disposições duráveis do organismo; b) apropriado pelo acesso a livros, obras de arte, produtos tecnológicos; e c) institucionalizado pela posse de certificados escolares e outras distinções simbólicas (BOURDIEU, 2007). Este conceito aparece ligado ao de cultura escolar, principal categoria trabalhada pelos autores, a qual é concebida como toda a vida de uma instituição educativa, incluindo-se os modos de experimentá-la, as visões de mundo, discursos e práticas (VIÑAO FRAGO, 2001), para além das normas que transmitem conhecimentos, incorporam comportamentos e definem condutas (JULIA, 2001). Entretanto, não é possível falarmos de uma cultura escolar única e sim de culturas escolares, produzidas por uma bricolagem em que cada escola recorta aqueles aspectos da cultura social que mais Ihe interessam ou lhes é possível, e os submetem a um processo de recriação (FORQUIN, 1993); isto é, por exemplo, o que acontece com as disciplinas escolares: longe de serem apenas adaptações das disciplinas acadêmicas, elas constituem saberes autônomos que têm na escola o seu lugar de produção (CHERVEL, 1990). 
O perfil elitizado do Colégio de Aplicação da Universidade Federal do Rio de Janeiro foi demonstrado por Gláucia Moreira Monassa Martins em sua tese, Prestígio Escolar: uma corrida de obstáculos - um estudo sobre o Colégio de Aplicação da UFRJ, defendida em 2015 na Universidade Estadual de Campinas quando enfatiza o nível socioeconômico dos bairros em que a referida instituição esteve situada ao longo da sua trajetória, a saber que

[...] Praia de Botafogo (de 1948 até 1951), Laranjeiras (de 1951 até 1958) e Lagoa Rodrigo de Freitas, em limites do Bairro Jardim Botânico (de 1958 até os dias atuais), estão localizados na zona sul da cidade, área nobre e valorizada pela especulação imobiliária e que concentra grupos sociais bem situados economicamente (MARTINS, 2015, p.93).

Valeska Alessandra de Lima, em sua dissertação Colégio de Aplicação da UFRGS: práticas educativas adormecidas entre o arquivo e a memória oral (1954-1981), defendida em 2016 na Universidade Federal do Rio Grande do Sul, abordou o aspecto seletivo daquela instituição escolar, a qual funcionou até 1996 no campus central da referida universidade - no centro da capital gaúcha, verificando, entre outros aspectos, a predominância de filhos da elite intelectual portalegrense na composição do seu alunado.

\begin{abstract}
Eram esperados estudantes muito qualificados. Mas como seriam selecionados? Aplicavam-se testes de inteligência, bem como os exames de admissão. Esses procedimentos avaliativos evidenciavam movimentos realizados pelo CAP, na intenção de cumprir seu papel de escola experimental, na qual se busca selecionar apenas os alunos melhor classificados, notadamente, aqueles pertencentes a uma camada intelectualmente favorecida (LIMA, 2016, p.112).
\end{abstract}

Martha Suzana Cabral Nunes, cuja dissertação, O Ginásio de Aplicação da Faculdade Católica de Filosofia de Sergipe (1959-1968) foi defendida em 2008 na Universidade Federal de Sergipe, ao discorrer sobre a criação desse estabelecimento, mostrou a sua importância no contexto de expansão do ensino secundário em Aracaju. O bairro São José, onde funcionava aquela faculdade, havia se formado com a construção de casarões pelas famílias da chamada "alta sociedade sergipana", as quais se retiravam do centro da cidade (cada vez mais barulhento!) devido à multiplicação das atividades comerciais que agitavam o seu cotidiano. Acerca da origem social dos estudantes do referido ginásio

[...] a maioria dos alunos vinha de famílias tradicionais de Aracaju, cujos pais eram juízes de direito, gerentes comerciais, comandantes do exército, cirurgiões-dentistas, médicos, professores das faculdades sergipanas, funcionários públicos e advogados [...] famílias que faziam parte não só da intelectualidade aracajuana, como também da classe média ascendente proveniente principalmente das atividades comerciais desenvolvidas com o crescimento da capital [...] (NUNES, 2008, p.54). 
Em Florianópolis, na Universidade Federal de Santa Catarina, cujo campus construído no distrito da Trindade trouxe um ar de modernidade e progresso àquele bairro, 0 Ginásio de Aplicação fundado em 1961 (renomeado Colégio de Aplicação quando implantou o ensino médio, em 1970) passou por um processo de elitização estudado por Ademir Soares Luciano Júnior em sua dissertação Cultura escolar e perfil discente no Colégio de Aplicação da UFSC (1966-1973), realizada na Universidade do Estado de Santa Catarina. Segundo o autor,

[...] nesse intervalo, já predominavam no Colégio de Aplicação os mesmos setores da sociedade que frequentavam instituições privadas, situação que era confirmada pela própria instituição. A escola afirmava em relatório, que, em seu início contava com $70 \%$ de alunos do Abrigo de menores, depois crianças não abrigadas, mas de "baixo nível social", tendendo, na entrada da década de 1970, aos "bem nascidos", momento que esta passou a se perceber como um "Colégio de Elite" (LUCIANO JÚNIOR, 2010, p.15).

Na dissertação defendida na Universidade Federal de Pernambuco, "Sentidos Compartilhados sobre o Colégio de Aplicação da UFPE: um estudo com pais e estudantes" Gisele Gomes de Almeida analisa a representação de instituição bem sucedida que se deve principalmente à sua clientela caracterizada como "camada média intelectualizada".

A maior parte dos estudantes reside em bairros prestigiosos localizados na zona norte da cidade do Recife (43.3\%) como Casa Forte, Poço da Panela, Apicucos, Jaqueira, Espinheiro, Madalena, Parnamirim e Torre, seguidos de bairros localizados na zona sul da cidade e na região metropolitana (25\%) em bairros como Boa Viagem, Piedade e Candeias. Parcela do grupo (20.8\%) reside na Cidade Universitária, Várzea e outros bairros próximos à universidade: Iputinga e Torrões. Um grupo pequeno de estudantes (10.8\%) reside nas periferias da cidade do Recife, mais precisamente no Barro, Estância, Ibura e Jardim São Paulo (ALMEIDA, 2014, p.128-129).

\section{A UNIVERSIDADE FEDERAL DO MARANHÃO E O COLÉGIO UNIVERSITÁRIO}

No Maranhão, o surgimento do Colégio Universitário coincide com a origem da Universidade Federal. Pela Lei ${ }^{\circ}$ 5.152, de 21 de outubro de 1966, a união assumiu o controle da antiga Universidade Católica e das Faculdades Federais de Direito, Odontologia e Farmácia, sendo instituída a Fundação Universidade do Maranhão (FUM), no intuito de conduzir o processo de implantação e estruturação da nova universidade que deveria erigir-se como uma "instituição de ensino superior, de pesquisa e de estudo em todos os ramos do saber, visando, imediatamente, a contribuir para a solução de problemas regionais de natureza econômica, social e cultural" (BRASIL, 1966, p. 279). Neste período, o país vivia os primeiros anos de uma ditadura civil-militar. A principal estratégia de legitimação do regime político consistia na difusão da ideologia desenvolvimentista, cujo porta-voz foi o 
governador José Sarney eleito em 1965 no Maranhão. Nesse contexto, o governo estadual saudou a chegada da instituição, sobretudo porque "era plano do recém-instalado governo [de] recorrer à universidade para a preparação de recursos humanos para preenchimento e expansão do seu quadro de pessoal" (PINTO, 1982, p.185).

Nos anos seguintes, novas unidades seriam acrescidas a esta estrutura. Assim, no dia 20 de maio de 1968, pela Resolução $n^{\circ} 42$ do Conselho Diretor da Fundação da Universidade Federal do Maranhão, foi criado o Colégio Universitário, cuja finalidade era:

\begin{abstract}
a) [...]contribuir para a preparação de candidatos aos concursos de habilitação para o ingresso nos estabelecimentos de ensino superior; b) ministrar o ensino diversificado da $3^{a}$ série [colegial] às diversas áreas; c) dar orientação adequada ao aluno para que este pudesse fazer opção profissional [...] O objetivo inicial era oferecer o ensino diversificado da $3^{\mathrm{a}}$ série, do então Ensino Médio, nas áreas humanísticas, de saúde e tecnológica [...] (Relatório do COLUN/UFMA, 1985, p.1).
\end{abstract}

Nessas diretrizes, percebe-se o caráter propedêutico que se imprimia ao Colégio no seu nascedouro, o que permite traçar uma continuidade no trajeto do ensino secundário brasileiro, destacando-se a existência de diferentes "tipos de ensino [...] para alunos provenientes de classes sociais diferentes" (NUNES, 1979, p.26), o que implica numa heterogeneidade das modalidades escolares que constituíram as escolas secundárias desde o alvorecer dos tempos republicanos. Destarte, é importante observar que, mesmo ante o quadro de carência educacional que ainda caracterizava o estado do Maranhão no final dos anos 1960, a oferta do Ensino Médio no Colégio Universitário não começa pela primeira série, mas pela terceira, o que parece reforçar o perfil inicial de curso preparatório para selecionar os futuros estudantes de graduação da universidade recém-criada.

Sediado inicialmente no Palácio Cristo Rei, onde também estavam a reitoria e a Faculdade de Filosofia, Ciências e Letras, o Colégio era dirigido pela professora Liene Sampaio Teixeira, docente da UFMA e lotada nesse prédio, que atuava na formação de professores tendo em vista que ali funcionavam os cursos de licenciatura; com foco na orientação dos candidatos aos cursos de graduação, os estudantes do $3^{\circ}$ ano colegial, nesse período, cursaram disciplinas como Português, Matemática, Língua Estrangeira (Espanhol, Francês ou Inglês), Cultura Geral, Educação Moral e Cívica, organizadas em um tronco comum, e uma parte diversificada, de acordo com os interesses da área de formação escolhida para realizar o concurso de habilitação na universidade. $\mathrm{Na}$ área humanística as disciplinas de História do Brasil, História Geral, Filosofia, Sociologia, e Geografia; como também na área de saúde e tecnológica eram proporcionadas Física, Química, Biologia e Desenho.

Em 1972, na conjuntura de ampliação da escolaridade obrigatória (de quatro para oito anos) e da divisão do currículo a nível nacional em dois núcleos: o comum (para todo o território brasileiro) e o diversificado (adaptado à realidade local), que enfatizava as habilitações profissionais para os estudantes do $2^{\circ}$ grau (unificação dos cursos colegial e técnico), tendo como pano de fundo a modernização industrial que demandava novas qualificações 
- mudanças estabelecidas pela Lei n 5.692, de 11 de agosto de 1971; o Colégio Universitário, então situado à Rua Viana Vaz, $n^{\circ} 280$, na Praça Quinta do Macacão (centro histórico de São Luís), reformulou o seu regimento interno, no qual determinou-se a ampliação da oferta para os três anos do $2^{\circ}$ grau e a instituição adaptou-se ao perfil de um Colégio de Aplicação, "[...] transformando-se em campo de estágio, experimentação e aplicação da Faculdade de Educação" (SANTOS, 2012, p.61), esta última desmembrada da antiga Faculdade de Filosofia, Ciências e Letras.

Entretanto, é preciso, fazer a seguinte ponderação: apesar do seu vínculo com a Faculdade de Educação, que o aproximou das características inerentes a outros Colégios desta natureza (segundo a constituição de um campo de estágio; a construção de um laboratório de experimentação de novas metodologias de ensino; a formação de um ambiente propício às pesquisas educacionais) e, da própria localização da instituição à época ao centro histórico, onde estavam os cursos de licenciatura da UFMA, facilitando-se o intercâmbio com docentes e alunos destas faculdades; mesmo assim, tal adaptação regimental não garantiu o desenvolvimento daquelas funções, até pela falta de espaço e pela estrutura inadequada, visto que continuou com um pequeno grupo de professores e sem sede própria; o que implicava numa inevitável limitação no que se refere ao seu potencial investigativo, à capacidade de contribuir para a melhoria do ensino e às trocas mais significativas com a comunidade escolar.

Além disso, a retirada das disciplinas de Filosofia e Sociologia² e a inserção de Organização Social e Política do Brasil demonstra o peso da ditadura civil-militar. Assim, passou-se a ofertar um currículo centrado nas seguintes disciplinas: Português, Matemática, Língua Estrangeira, Organização Social e Política do Brasil, Física, Química, Biologia, História e Geografia. As habilitações profissionais (Administração, Estatística e Secretariado) só foram implementadas em 1974, já com o Colégio em novo endereço: Rua das Hortas, $n^{\circ}$ 109 "A", onde os três anos do $2^{\circ}$ grau ofereciam um núcleo Comum (Português, Matemática, Língua Estrangeira, Física, Química, Biologia, Educação Moral e Cívica, Organização Social e Política do Brasil, Educação Artística, Educação Física e Programas de Saúde) e uma parte diversificada que correspondia àquelas habilitações.

Em 1975, ocorreu sua primeira transferência para o campus universitário do Bacanga, onde permaneceu até o final dessa década. Ali, continuou com o $2^{\circ}$ grau nos moldes da Lei 5.692/1971, mantendo bom desempenho nos vestibulares da universidade; fase marcada pela restrição das suas matrículas aos filhos e parentes de servidores da UFMA. Situação insustentável, se levarmos em conta que o ensino de $1^{\circ}$ e $2^{\circ}$ graus reclamava modificações urgentes no que se refere à quantidade e qualidade das instalações escolares,

2 A demonstração de força política empreendida por grupos conservadores da sociedade brasileira nestes últimos cinco anos, também tem recrudescido o debate sobre a importância dessas disciplinas no currículo do Ensino Médio, já que as novas diretrizes para este nível, que ganham forma na Base Nacional Comum Curricular (2018), tendem a diluir Filosofia, Sociologia, História e Geografia em "Ciências Humanas e sociais aplicadas" que, por sua vez, tornam-se optativas. 
aos métodos empregados em sala de aula e à formação de professores; defasagem que atingia a própria universidade, cujos vestibulares apresentavam assombrosos índices de reprovação, sendo ainda mais decepcionante a evasão nos cursos superiores.

Diante desse panorama, a universidade reestruturou o Colégio Universitário tendo em vista que não cumpria o papel esperado como Colégio de Aplicação, pois "[...] não conseguiu alcançar integralmente seus objetivos por razões de ordem técnica e administrativa e a inadequação às diretrizes preconizadas pela legislação específica." (COLUN, 1980, p.5), dada à ausência de uma política interna da universidade no sentido de valorizá-lo na sua singularidade, como escola-laboratório focada na experimentação e diálogo constante com as licenciaturas, o que pressupunha uma série de condições, as quais não se usufruíam naquele momento, sendo que a inexistência de um prédio escolar diminuía o seu potencial no desenvolvimento não só das práticas educativas "[...] que atuam e influenciam a vida dos sujeitos, de modo amplo, difuso e imprevisível" (FRANCO, 2006, p.536); como também das práticas pedagógicas "[...] que se realizam para organizar/potencializar/interpretar as intencionalidades de um projeto educativo [...] por um pensamento reflexivo sobre o que ocorre [...] bem como por um pensamento crítico do que pode ser a prática educativa" (FRANCO, 2006, p. 537-538) e que caracterizavam outros Colégios de Aplicação pelo Brasil; demandas que exigiam um espaço exclusivo e um tempo específico onde se pudesse impor a ordem escolar (VINCENT; LAHIRE; THIN, 2001).

Ao mesmo tempo, a Secretaria Estadual de Educação (SEDUC) tentava colocar em funcionamento os Ginásios Polivalentes construídos no âmbito dos acordos entre o Ministério da Educação (MEC) e a Agência dos Estados Unidos para o Desenvolvimento Internacional (USAID) via Programa de Expansão e Melhoria do Ensino (PREMEN). Ginásios concebidos como escolas-modelo na difusão de um currículo capaz de unir humanismo, ciência e tecnologia (PEDROSA; BITTENCOURT JÚNIOR, 2015), visando aperfeiçoar o sistema de ensino de primeiro e segundo graus no Brasil.

Uma dessas obras, construída no bairro periférico da Vila Palmeira, foi objeto do convênio firmado entre a UFMA e a SEDUC com o fim de reestruturar o Colégio Universitário, o qual deveria garantir o uso permanente do prédio até então subutilizado devido à ineficiência das políticas educacionais como marca dos governos maranhenses ${ }^{3}$. Reestru-

3 Segundo Castellanos, "A instantaneidade cinematográfica dos governos no Maranhão do I e II Reinado, e a não continuidade ou má administração no curral governamental (MEIRELES, 2001) sustentada pelas lutas do dualismo partidário trouxeram consigo o não cumprimento de reformas ao longo prazo, seja no cenário social, seja no educacional. Presidentes de expedientes que não podiam (pela dinamicidade na constante mudança administrativa das suas funções) planejar reformas que visassem o melhoramento do bem público e muito menos executá-las; se considerarmos que pela vaidade pessoal de alguns governantes, em vez de se complementarem algumas grandes obras já começadas, preferiam descartá-las, apagando assim a imagem pública de seus antecessores" (2007, p. 82). Como exemplos desse marasmo de políticas sem aplicação, podemos citar também, a instituição das escolas normais destinadas à formação de professores que, segundo os próprios presidentes de província e/ou governantes do estado, "não teve o efeito esperado", principalmente porque era enorme o descompasso entre a preparação teórica recebida pelos formandos e a difícil realidade das escolas no interior do Maranhão (CASTELLANOS, 2007), e o funcionamento dos grupos escolares que, na verdade foram marcados pela precariedade em termos de instalações físicas e de formação/valorização dos seus professores (SILVA, 2017). 
turação que se julgava necessária porque o público atendido no campus não era suficiente para dinamizar o estágio docente, haja vista que a sua pequena dimensão e a restrição a um grupo muito reduzido de alunos, além de absorver poucos estudantes da graduação, impedia que esses professores em formação tivessem a oportunidade de desenvolver práticas pedagógicas mais significativas. Levando em conta a carência de pessoal com diploma de nível superior, era muito comum que os profissionais do ensino de $1^{\circ}$ e $2^{\circ}$ graus não fossem ainda licenciados; eram educadores leigos de escolas públicas e privadas, com suas licenciaturas em andamento, razão pela qual o projeto previa um Colégio de Aplicação com prerrogativas mais ampliadas, almejando uma "contribuição natural [ao] aprimoramento e elevação da qualificação dos docentes de $1^{\circ}$ e $2^{\circ}$ graus do Maranhão." (COLUN, 1980, p.6).

Sua presença na Vila Palmeira reveste-se de uma relevância histórica, dadas as dimensões do prédio situado na periferia da cidade; bairro que começava a se formar na esteira do crescimento demográfico de São Luís. A expansão da malha urbana ludovicense no contexto de industrialização e metropolização da ilha trouxe consigo inúmeros problemas sociais com a formação de áreas carentes, decorrentes de ocupações desordenadas, aumentando a segregação socioespacial. Eram as "invasões" marcadas pela violência e ausência do estado (SILVA, 1987); entretanto, na Vila Palmeira, com uma gigantesca obra pública, esta instituição vislumbrava-se como uma amenização desse quadro.

Portanto, os objetivos do projeto educativo que deu origem ao COLUN (sigla criada na Vila Palmeira) iam desde a função de escola-laboratório, com a intenção de difundir um novo modelo de ensino, até a tarefa civilizatória de preparar crianças e adolescentes dos meios populares para o exercício da cidadania dentro dos limites reais, adequando-os à ordem social mediante uma "educação que [direcionasse] a sociedade, promovendo seu desenvolvimento, sua ordem, evolução, organização e preparo social” (COLUN, 1980, p.7). O regimento interno, elaborado em 1982, reforçava esses objetivos de

oferecer ensino de $1^{\circ}$ e $2^{\circ}$ graus à população de Vila Palmeira [...] servir de campo de estágio para os cursos da UFMA, notadamente os de licenciatura, proporcionando a articulação dessa universidade com o ensino de $1^{\circ}$ e $2^{\circ}$ graus", [devendo] "constituir-se em local de desenvolvimento de tecnologias de ensino, pesquisas e experiências educacionais [...] integrar a comunidade do bairro em atividades diversas, com vistas a sua participação no processo educativo" [e ainda] "propiciar contínuo aperfeiçoamento aos docentes, técnicos e pessoal administrativo da escola, incentivando a participação em cursos, círculos de estudos, etc. (COLUN, 1982, p. 2).

As ações previstas, embora apareçam de forma articulada, deixam latentes algumas disputas que colocariam em posições divergentes a Universidade Federal do Maranhão e a comunidade assistida pela escola no que se refere ao perfil institucional a ser traçado em sua trajetória. No mesmo documento aparecem lutas de representações que ocorrem por causa das diferentes ideologias e do complexo jogo de interesses sociais (BARROS, 2003), 
ora classificando o Colégio como escola comunitária, ora enfatizando o seu vínculo com a UFMA.

Logo nos primeiros anos de funcionamento na Vila Palmeira o COLUN teve suas funções ampliadas, não apenas pela oferta do $1^{\circ} \mathrm{e}$ do $2^{\circ}$ graus, mas também porque o estágio de estudantes da graduação estendeu-se para além das licenciaturas, incluindo alunos dos cursos de Biblioteconomia, Bioquímica, Enfermagem, Medicina, Odontologia, Serviço Social. Com isso, a escola adquiria experiência na oferta de projetos de extensão, além da função principal de escola-laboratório de ensino e pesquisa. A política de ensino, pesquisa e extensão ofertada na Vila Palmeira a partir de 1980 configura-se como produto cultural, na medida em que "para a sua produção, são movimentadas determinadas práticas culturais e também representações [que irão] difundir novas representações e contribuir para a difusão de novas práticas" (BARROS, 2003, p.160).

O corpo profissional da escola aumentou consideravelmente com novos concursos realizados em 1980 e 1981, que visavam atender as múltiplas tarefas demandadas a partir da reestruturação. Além da equipe docente, ingressaram profissionais técnico-administrativos e especialistas (engenheiro, dentista, agrônomo, psicólogo, assistente social e outros). Estes são produtores culturais, pois prescrevem objetos ou produtos, na medida em que são responsáveis pela efetivação e condução da experiência pedagógica a partir da instituição escolar, vista como agência produtora e difusora de cultura, uma vez que as "agências de produção e difusão cultural também se encontram no âmbito institucional: os sistemas educativos, a imprensa, os meios de comunicação, as organizações socioculturais e religiosas" (BARROS, 2003, p.148).

Por sua vez, os alunos e membros da comunidade que participaram desse momento inicial de reestruturação do COLUN, ao apropriarem-se dos serviços educacionais oferecidos, tornam-se receptores culturais e participam da criação dos saberes (disciplinas) e práticas escolares (conselhos, grêmio, jogos, formaturas etc). Enfim, todos eles - objetos culturais, produtores e receptores de cultura - circulam entre as práticas e representações que constroem a trajetória do Colégio Universitário.

Tudo isso dava ao estabelecimento um status diferenciado perante a sociedade ludovicense, já que a instituição possuía recursos humanos e materiais incomuns para a realidade da maioria das escolas públicas brasileiras. Por isso, houve cada vez mais interesse das famílias para que seus filhos estudassem no Colégio: dos estudantes universitários que desejavam a experiência do estágio neste ambiente e; daqueles que já faziam parte do quadro da instituição, pelo prestígio que este pertencimento Ihes outorgava. Em outras palavras, difundiu-se uma visão positiva do Colégio e ingressar nele passou a ser visto como instrumento de inserção social. Este modo de ver o COLUN é uma representação cultural (BARROS, 2003) e aparece na documentação analisada que o descreve, por exemplo, como "campo de excelência para todos os cursos da UFMA" (COLUN, 1990, p.3), em que "pudemos constatar o nível de qualidade atingido" (COLUN, 1991, p.5). Expressões que dão significado a esta instituição singular; representações compartilhadas para além 
dos muros escolares, no reconhecimento social de "uma escola de referência" (APRUMA INFORMA, 1999, p.9).

A estrutura física do Colégio, com uma grande área murada que abrigava os prédios do $1^{\circ}$ e $2^{\circ}$ graus equipados com laboratórios e oficinas, contribuía para dotar o COLUN desse caráter singular e inovador. É importante refletir sobre estes dados, pois "qualquer objeto material produzido pelo homem faz também parte da cultura - da cultura material, mais especificamente" (BARROS, 2003, p. 145), de modo que da própria materialidade escolar emergem imagens que trazem consigo uma representação positiva do Colégio Universitário.

Esta representação construída sobre o Colégio gerou várias práticas culturais no seu interior. Meios através dos quais a cultura se produz (BARROS, 2003). Práticas responsáveis pela organização da vida escolar. O organograma administrativo do COLUN possuía a superintendência, unidade responsável pela administração geral que atuava no controle do patrimônio material e dos recursos humanos, exercendo tarefas burocráticas; as direções de ensino de $1^{\circ}$ e $2^{\circ}$ graus que cuidavam das questões disciplinares e do controle de carga horária; o Núcleo de Assistência Pedagógica (NAP), com serviços de supervisão pedagógica e de apoio às atividades escolares; o Núcleo de Assistência ao Educando (NAE), de orientação educacional, assistência social, psicológica e médica. Além dessas unidades administrativas, havia o Conselho de professores, que participava do planejamento do ano escolar; o Conselho de Classe, onde a equipe pedagógica tomava conhecimento do desempenho de cada aluno e adotava medidas interventivas, quando necessário; a associação recreativa, cívica e cultural (ASSORCIC), formada por alunos encarregados de organizar comemorações cívicas e atividades culturais, esportivas e literárias e a associação de pais e comunitários, que deveria atuar na integração da escola com a comunidade (COLUN, 1982, p.4).

O Colégio Universitário no contexto da reforma do ensino médio (nova fase!) passaria a oferecer $1^{\circ}$ e $2^{\circ}$ graus em consonância com a Lei $n^{\circ} 5.692 / 1971$, que assim denominava as etapas da educação básica que hoje chamamos de Ensino Fundamental e Ensino Médio respectivamente. Ademais, suas turmas deveriam ser compostas, prioritariamente, por alunos moradores do Bairro. A mudança de sede para a Vila Palmeira representou uma ruptura na trajetória do Colégio Universitário, pois se tratava de uma comunidade carente da periferia de São Luís (SILVA, 1987). O aspecto periférico do Bairro e o perfil social dos estudantes contrastavam com o papel anterior do colégio: uma escola de classe média com finalidade propedêutica, tornando significativo o momento de transição, quando da implantação do COLUN na Vila Palmeira, pois nesta ocasião deixa de atender apenas os filhos dos servidores, que teriam um determinado capital cultural (BOURDIEU, 2007), e volta-se para um público mais carente.

Além das disciplinas do núcleo comum e da formação especial, dividida em iniciação para o trabalho (no $1^{\circ}$ grau) e habilitação profissional (no $2^{\circ}$ grau), quem se matriculasse deveria participar de várias atividades educativas: banda, coral, teatro, hora cívica, forma- 
turas e festividades escolares. Assim, projetava-se um ideal de civilidade inerente ao modo de socialização segundo o qual a forma escolar participa de uma ordem urbana em que

[...] colocar todas as crianças -'até mesmo as mais pobres'- em escolas, aparece como um vasto empreendimento que se poderia chamar de ordem pública, com a condição de não reduzi-lo a simples ato de dominação, [pois] "trata-se de obter a submissão, a obediência, ou uma nova forma de sujeição" [através de] "regras que são constitutivas da ordem escolar" (VINCENT; LAHIRE; THIN, 2001, p.14).

Nesse sentido, a formação profissional integrou o novo currículo desde $01^{\circ} \mathrm{grau}$, onde havia algumas disciplinas especiais, como: técnicas agrícolas, comerciais, industriais e a educação para o lar; no $2^{\circ}$ grau, os discentes deveriam optar por uma habilitação profissional: Administração, Mecânica, Eletricidade, Construção Civil, Saúde e Magistério. Esta situação seria modificada em parte por uma reforma curricular ocorrida em 1984 no contexto da Lei $n^{\circ} 7.044 / 1982$, que alterava a Lei $n^{\circ} 5.692 / 1971$, estabelecendo o fim da obrigatoriedade do ensino profissionalizante a nível de $1^{\circ}$ e $2^{\circ}$ graus, mantendo a disciplina de Orientação para o trabalho. No COLUN a reforma procurou criar condições para ampliar a formação geral, fazendo com que esta se sobrepusesse à formação especial, que, entretanto, não foi extinta. Na prática, isso se traduzia em uma ampliação da carga horária das disciplinas comuns ou gerais, para "formar no aluno uma sólida formação geral, ampla e crítica da realidade em que se inserir, podendo transferir seus conhecimentos para a vida prática no processo de reorganização de suas experiências" (COLUN, 1984, p.2).

Por toda a década de 1980, enquanto o Brasil vivia sob o impacto do processo de redemocratização, que culminou com a promulgação da Constituição Federal de 1988 e as eleições presidenciais de 1989, o COLUN se movimentava na direção de uma maior autonomia em relação à universidade, contando com a participação da comunidade que, por sua vez, se movia em seu entorno, configurando-se uma descentralização administrativa que criou condições para a existência de uma cultura escolar democrática manifestada pela atuação da Associação de pais e comunitários e da Associação dos discentes, bem como da participação de alunos nas reuniões dos Conselhos de Classe, onde eram debatidas as questões do processo de ensino-aprendizagem; e no Conselho Diretor, que deveria contar com um representante de cada segmento da instituição.

Estas transformações na dinâmica organizacional da escola obrigam a "(...) enxergar o problema sob os novos ângulos das estratégias cotidianas" (BARROS, 2003, p.151), considerando a ação dos professores, alunos e demais agentes implicados no cotidiano escolar. Sujeitos que, face às estratégias de imposição do modelo burocrático por parte da universidade, desenvolveram mecanismos táticos de resistência na luta pela participação democrática na gestão do Colégio.

Aqui, é necessário questionar se mesmo em regimes ditatoriais ou com tendências autoritárias não é possível identificar nos sistemas construídos, sejam eles religiosos e políticos, sejam educacionais, relações de força entre as estratégias dos que detêm um lugar e 
um poder de controle e as táticas de apropriação dos que desobedecem, inventam espaços imprevistos de atuação e alteram algum produto criado por aquelas estratégias (CERTEAU, 2012). E se este não é precisamente o caso que temos em mira, considerando que o Colégio Universitário da UFMA se consolidou dentro de uma estrutura educacional marcada pela fragilidade política das ciências humanas, e enquanto Filosofia, Sociologia, Geografia e História dividiam espaço com Educação Moral e Cívica, Organização Social e Política do Brasil e disciplinas profissionalizantes, a cultura escolar democrática fabricou seu espaço entre os muros da instituição.

Em plena vigência de uma legislação educacional hostil ao desenvolvimento intelectual e à participação política da juventude; com a Lei 5.692/1971 ainda em vigor, apesar das modificações introduzidas pela Lei 7.044/1982; mantinha-se o foco dos estudos sociais e humanos na inculcação da cultura cívico-patriótica. Mas nem por isso impediu-se o fluir do espírito participativo, a consciência política e a capacidade de crítica, principalmente entre os estudantes do $2^{\circ}$ grau. Situação que remete ao debate atual sobre a Base Nacional Comum Curricular, o futuro do Ensino Médio e o lugar do Colégio Universitário nessa nova relação histórica de forças em que um grupo impõe "[...] a sua maneira de dar a ver o mundo, de estabelecer classificações e divisões, de propor valores e normas, que orientam o gosto e a percepção, que definem limites e autorizam os comportamentos e os papéis sociais". (PESAVENTO, 2012, p. 22), enquanto outros oferecem "[...] resistência [...] em âmbitos culturais [...] ressalvado [...] o sentido moderno de cultura que inclui os sistemas de hábitos e comportamentos e o âmbito das práticas e representações". (BARROS, 2003, p. 151).

Nesse sentido, propomos uma análise mais específica, em perspectiva histórica, sobre a trajetória recente dessa etapa da educação básica no COLUN/UFMA, privilegiando o marco representado pela Lei de Diretrizes e Bases da Educação Nacional (promulgada em 1996), que, ao prever para o Ensino Médio um caráter formativo mais abrangente, ilumina um horizonte de valorização daquelas disciplinas proscritas do $2^{\circ}$ grau nos tempos de autoritarismo civil-militar e ao mesmo tempo acende reações contrárias a essa nova orientação curricular no seio das forças conservadoras da sociedade brasileira.

Protagonistas dessa disputa, profissionais do ensino de Filosofia, Sociologia, Geografia e História, membros do corpo docente do COLUN, vêm desenvolvendo sua produção cultural no sentido de solidificar essa parte importante do currículo do Ensino Médio no Colégio de Aplicação, fazendo parte dessa produção as práticas de estágio supervisionado dos licenciando da Universidade, como participantes na elaboração dos saberes escolares constituidores dessas disciplinas. Realização histórica que ocorre não sem dificuldades: a impopularidade das ciências humanas em geral, a pouca tradição escolar e o nível de leitura dos alunos são obstáculos difíceis de enfrentar; barreiras resultantes do baixo investimento em educação pública, pois não é de interesse dos dirigentes nacionais que as pessoas comuns estudem com profundidade e sejam dotadas de alto nível de criticidade.

Desse campo de forças em que "as representações apresentam múltiplas configurações, e pode se dizer que o mundo é construído de forma contraditória e variada, pelos di- 
ferentes grupos do social" (PESAVENTO, 2012, p.22), emergem diretrizes opostas, dentro da conjuntura histórica de polarização ideológica que caracteriza as primeiras décadas do século XX. Assim, se a Lei $\mathrm{n}^{\circ} 11.684$, de 02 de junho de 2008 instituiu a obrigatoriedade do ensino de Filosofia e Sociologia no Ensino Médio brasileiro e nesse contexto, a distribuição de livros didáticos fortaleceu o estatuto de disciplina escolar destas duas áreas e potencializou o ensino de História e Geografia; na contramão aproximadamente uma década depois, a Lei 13.415, de 16 de fevereiro de 2017, conhecida como Reforma do Ensino Médio, ao projetar a Base Nacional Comum Curricular (BNCC), traz a ideia dos itinerários formativos.

Art. 36. O currículo do ensino médio será composto pela Base Nacional Comum Curricular e por itinerários formativos, que deverão ser organizados por meio da oferta de diferentes arranjos curriculares, conforme a relevância para o contexto local e a possibilidade dos sistemas de ensino, a saber:

I - linguagens e suas tecnologias

II - matemática e suas tecnologias

III - ciências da natureza e suas tecnologias

IV - ciências humanas e suas tecnologias

$V$ - formação técnica e profissional. (BRASIL, 2017, p.1)

Levando em conta que a BNCC deve concentrar apenas $40 \%$ da carga horária total, destinando-se os $60 \%$ restantes aos itinerários formativos, significando na prática que: 1) somente Língua Portuguesa, Matemática e Inglês serão disciplinas obrigatórias; 2) Filosofia e Sociologia, Geografia e História se tornarão "estudos e práticas" também obrigatórios, mas sem o estatuto de disciplinas; 3 ) o estudante do ensino médio deve ter "liberdade" para escolher o(s) itinerário(s) pedagógico(s) que melhor se adeque(m) ao seu perfil, sem ter a maturidade intelectual suficiente para esse tipo de escolha; 4) quando a escolha recaia sobre ciências humanas, nelas estarão diluídas a Geografia, a História, a Filosofia e a Sociologia; na verdade, tanto a Lei 13.415/2017, quanto a Base Nacional Comum Curricular (2018) trazem a possibilidade de eliminar disciplinas, principalmente, as que compõem o grupo das ciências humanas, dado o repertório de desestímulo ao seu estudo.

Diretrizes que repõem, embora em outro contexto e novos moldes, a velha questão da fragmentação curricular responsável pela heterogeneidade das modalidades de ensino que caracterizaram a escolarização secundária desde as primeiras tentativas de sua unificação na década de 1930. Após atravessar as conturbações políticas do século XX, entre ditaduras e interregnos democráticos, com várias mudanças na sua organização sem que nenhuma delas atingisse as finalidades do ensino oferecido e the modificasse a identidade, limitando-se só ao dualismo entre a preparação para o ensino superior e a formação profissionalizante, na última transição democrática desenham-se os primeiros esboços de um ensino médio com terminalidade específica que aponta para a formação integral. Atualmente, porém, o refluxo das forças políticas conservadoras coloca diante dos olhares mais lúcidos um cenário de incertezas para o ensino médio. Nesse contexto, enxergamos o 
Colégio Universitário ${ }^{4}$ como um palco de lutas, onde certamente os próximos anos serão marcados pela tensão entre as estratégias de imposição de quem está no poder (simbólico ou não) que se concretizam na nova legislação educacional como lugar de disputa/tensões/ concessões entre interesses pessoais e partidários e as táticas de resistências forjadas no espaço escolar pelos professores, estagiários e alunos que não aceitam transferências de códigos e condutas que visam concepções discriminatórias de grupos e fazem deste colégio, um lugar de luta, oposição e disputa como resultado da própria apropriação crítica que põem em causa as intencionalidades políticas em curso.

\section{CONSIDERAÇÕES FINAIS}

Como vimos, as pesquisas sobre Ginásios e Colégios de aplicação em outros estados brasileiros dão conta de Colégios caracterizados pela elitização, que geralmente atendem alunos de bairros situados nas áreas mais estruturadas de cidades como Rio de Janeiro, Florianópolis, Porto Alegre, Aracaju e Recife. Nestas instituições, estudavam alunos pertencentes aos estratos sociais que já tinham acesso a bens culturais que os diferenciavam dos estudantes de outras escolas públicas. Nesse aspecto, o Colégio Universitário da UFMA parece tornar-se uma exceção, porque no período de sua consolidação estava localizado em um bairro popular e a ação exercida pelo seu corpo profissional e por estagiários dos cursos de licenciatura da UFMA estimulou a vários moradores do Bairro e de bairros próximos a disputarem o acesso e a permanência na instituição, em busca das possibilidades do consumo de bens culturais que a instituição oferecia.

Acreditamos que a experiência do Colégio Universitário na Vila Palmeira, ao oportunizar trocas significativas entre o mundo acadêmico e a realidade da escola pública, proporcionou um modelo de estágio supervisionado capaz de ultrapassar a mera obrigação curricular. Nessa perspectiva, defendemos que por situar-se numa área da cidade com características socioespaciais e socioculturais representativas da média das comunidades urbanas brasileiras, este Colégio cumpriu seu papel de escola-laboratório de experimentação pedagógica contribuindo para a melhoria do ensino público nesse período, visto que, se levarmos em conta a atuação profissional dos egressos das várias licenciaturas da UFMA, de alguma forma as reflexões e práticas processadas naquele espaço foram difundidas para outras escolas do sistema oficial de ensino.

Quanto às últimas décadas, percebemos o COLUN atingido pelas descontinuidades verificadas nas reformas educacionais brasileiras, principalmente se considerarmos as diretrizes curriculares do ensino médio que, na década de 1990, apontavam para um caráter formativo mais amplo, com a inclusão de Filosofia e Sociologia (tornadas obrigatórias no final da década seguinte) e hoje, conforme a Base Nacional Comum Curricular e seus itinerários formativos trazem uma concepção restrita de formação escolar, na contramão do projeto educativo perseguido pelo Colégio Universitário.

4 Desde 2006, instalado em sua nova sede na Cidade Universitária Dom Delgado (campus do Bacanga). 
Por fim, a nosso ver, uma ação preeminente que emana dos resultados alcançados com esta pesquisa, e que julgamos de um singular contributo para os estudos sobre o Colégio de Aplicação como modalidade escolar numa perspectiva histórica ainda pouco estudada, levando-se em conta o seu potencial no diálogo possível (mas ainda insuficiente!) com as universidades públicas, principalmente as federais, e com a educação básica; é precisamente, refletir sobre os obstáculos que dificultam a integração entre estes níveis de ensino no Brasil, desde a invenção dessa forma escolar no período imperial, que se vem sustentando até hoje na mudança inicial que se estabeleceu na relação pedagógica, a qual, paulatinamente, continua hierarquizada e polariza ainda mais as relações de poder entre educadores e educandos, além de ser projetada num campo de forças conturbado, onde a burocratização dos técnicos que legislam sobre este colégio (guiados por intencionalidades politicas perversas) e dos especialistas que a ele se reportam, estão longe da gramática escolar dessa modalidade de escola. 


\section{REFERÊNCIAS}

ALMEIDA, Gisele Gomes de. Sentidos Compartilhados sobre o Colégio de Aplicação da UFPE: um estudo com pais e estudantes. 2014. Dissertação (Mestrado em Educação) - Centro de Educação, Universidade Federal de Pernambuco, Recife, 2014.

BARROS, José D'Assunção. História cultural: um panorama historiográfico. Textos de história, Brasília, v.11, n.1/2, p.145-171, 2003.

BONTEMPI JÚNIOR, Bruno. Em defesa de "legítimos interesses": o ensino secundário no discurso educacional de O Estado de S.Paulo (1946-1957). Revista Brasileira de História da Educação, Campinas, n.12, p.121-158, jul./dez. 2006.

BOURDIEU, Pierre. Os três estados do capital cultural. In: NOGUEIRA, Maria Alice; CATANI, Afrânio (org.). Escritos de Educação. Petrópolis, RJ: Vozes, 2007. p.71-80.

CASTELLANOS, Samuel Luis Velázquez. Práticas de Leitura no Maranhão na Primeira República: entre apropriações e representações. 2007. Dissertação (Mestrado em Educação) - Centro de Ciências Sociais, Universidade Federal do Maranhão, São Luís, 2007.

CASTRO, César Augusto. Arquivos e Fontes na História da Educação. In: GONDRA, José Gonçalves; MACHADO, Maria Cristina Gomes; SIMÕES, Regina Helena Silva (Org.). História da Educação: Matrizes Interpretativas e Internacionalização. Vitória: EDUFES, 2017. p.226-252.

CERTEAU, Michel de. A invenção do Cotidiano: Artes de Fazer. Tradução Ephraim Ferreira Alves. 18.ed. Petrópolis: Vozes, 2012.

CHARTIER, Roger. A história cultural: entre práticas e representações. Tradução Maria Manuela Galhardo. 2.ed. Lisboa: Difel, 1988.

CHERVEL, André. História das disciplinas escolares: reflexões sobre um campo de pesquisa. Teoria \& Educação, Porto Alegre, n.2, p. 177-229, 1990.

FORQUIN, Jean-Claude. Escola e cultura: as bases sociais e epistemológicas do conhecimento escolar. Porto Alegre: Artes Médicas, 1993.

FRANCO, Maria Amélia do Rosário Santoro. Prática pedagógica e docência: um olhar a partir da epistemologia do conceito. Revista Brasileira de Estudos Pedagógicos, Brasília, v.97, n.247, p.534-551, set./dez. 2016.

HUNT, LYNN. A nova história cultural. São Paulo: Martins Fontes, 1992.

JULIA, Dominique. A Cultura Escolar como objeto histórico. Revista Brasileira de História da Educação, Campinas, v.1, n.1, p.09-43, jan./jun. 2001.

LIMA, Valeska Alessandra de. Colégio de Aplicação da UFRGS: práticas educativas adormecidas entre o arquivo e a memória oral (1954-1981). 2016. Dissertação (Mestrado em Educação) - Faculdade de Educação, Universidade Federal do Rio Grande do Sul, Porto Alegre, 2016. 
LUCIANO JÚNIOR, Ademir Soares. Cultura escolar e perfil discente no Colégio de Aplicação da UFSC (1966-1973). 2010. Dissertação (Mestrado em Educação) - Centro de Ciências Humanas e da Educação, Universidade Federal de Santa Catarina, Florianópolis, 2010.

MARTINS, Gláucia Moreira Monassa. Prestígio escolar: uma corrida de obstáculos - um estudo sobre o Colégio de Aplicação da UFRJ. 2015. Tese (Doutorado em Educação) - Faculdade de Educação, Universidade Estadual de Campinas, Campinas, 2015.

NUNES, Clarice. Escola e dependência: o ensino secundário e a manutenção da ordem. Rio de Janeiro: Achiamé, 1979.

NUNES, Martha Suzana Cabral. O Ginásio de Aplicação da Faculdade Católica de Filosofia de Sergipe (1959-1968). 2008. Dissertação (Mestrado em Educação) - Núcleo de Pós-graduação em Educação, Universidade Federal de Sergipe, Aracaju, 2008.

PEDROSA, José Geraldo; BITENCOURT JÚNIOR, Nilton Ferreira. Americanismo e educação para o trabalho no Brasil (1971-1974). Trabalho \& Educação, Belo Horizonte, v.24, n.1, p.11-30, jan./ abr. 2015.

PESAVENTO, Sandra Jatahy. História e História Cultural. Belo Horizonte: Autêntica, 2012.

PINTO, Maria Núbia Bonfim. Do velho ao novo: política e educação no Maranhão. 1982. Dissertação (Mestrado em Educação) - Instituto de Estudos Avançados em Educação, Fundação Getúlio Vargas, Rio de Janeiro, 1982.

SANTOS, Sandra Regina Rodrigues dos Santos. Gestão Democrática: representações e potencialidades na atuação do Conselho Diretor e na construção do Projeto Político Pedagógico - o caso do Colégio Universitário em São Luís (1989-1997). São Luís: EDUEMA, 2012.

SCHWARTZMAN, Simon; BOMENY, Helena Maria Bousquet; COSTA, Vanda Maria Ribeiro. Tempos de Capanema. São Paulo: Paz e Terra/Rio de Janeiro: Fundação Getúlio Vargas, 2001.

SILVA, Diana Rocha da. As casas de ensino no Maranhão: um estudo de sua representação no período republicano (1903-1912). 2017. Tese (Doutorado em Educação Escolar) - Faculdade de Ciências e Letras, Universidade Estadual Paulista "Júlio de Mesquita Filho", Araraquara, 2017.

SILVA, Maria do Socorro Moura da. Escola e comunidade: estudo das relações. São Luís: UFMA, 1987.

VIÑAO FRAGO, Antonio. Do espaço escolar e da escola como lugar: propostas e questões. In: VIÑAO FRAGO, Antonio; ESCOLANO, Agustin. Currículo, espaço e subjetividade. Rio de Janeiro: DP\&A, 2001. p. 59-89.

VINCENT, Guy; LAHIRE, Bernard; THIN, Daniel. Sobre a história e a teoria da forma escolar. Educação em Revista, Belo Horizonte, n. 33, p.7-47, jun. 2001. 


\section{FONTES}

\section{Legislação}

BRASIL. Decreto-Lei n 9.053, de 12 de março de 1946. Cria um ginásio de Aplicação nas Faculdades de Filosofia do país. Coleção de Leis da República. v.1, p.520-521, jan./mar. 1946. Rio de Janeiro: Imprensa Nacional, 1946.

BRASIL. Decreto-Lei n 9.092, de 26 de março de 1946. Amplia o regime didático das Faculdades de Filosofia e dá outras providências. Coleção de Leis da República. v.1, p.548-549, jan./mar. 1946. Rio de Janeiro: Imprensa Nacional, 1946.

BRASIL. Lei 11.684, de 02 de junho de 2008. Altera o art. 36 da Lei $n^{\circ}$ 9.394, de 20 de dezembro de 1996, que estabelece as diretrizes e bases da educação nacional, para incluir a Filosofia e a Sociologia como disciplinas obrigatórias nos currículos do ensino médio. Diário Oficial da União. Seção 1. Brasília, DF, ano CXLV, n.104, p.1, 03 jun.2008.

BRASIL. Lei $n^{\circ} 13.415$, de 16 de fevereiro de 2017. Altera as Leis $n^{\circ} 9.394$, de 20 de dezembro de 1996, que estabelece as diretrizes e bases da educação nacional e [ $\left.{ }^{\circ}\right] 11.494$, de 20 de junho de 2007, que regulamenta o Fundo de Manutenção e Desenvolvimento da Educação Básica e de Valorização dos profissionais da Educação, a Consolidação das Leis do Trabalho - CLT, aprovada pelo Decreto-Lei $n^{\circ} 5.452$, de $1^{\circ}$ de maio de 1943, e o Decreto-Lei $n^{\circ} 236$, de 28 de fevereiro de 1967; revoga a Lei no 11.161, de 5 de agosto de 2005; e institui a Política de Fomento à Implementação de Escolas de Ensino Médio em Tempo Integral. Diário Oficial da União: Seção 1. Brasília, DF, ano CLIV, n. 35, p.1-3, 17 fev. 2017.

BRASIL. Lei n 4.024, de 20 de dezembro de 1961. Fixa as Diretrizes e Bases da Educação Nacional. Coleção de Leis da República. v.7, p.51-66, out./dez. 1961. Brasília: Imprensa Nacional, 1961.

BRASIL. Lei $n^{\circ} 5.152$, de 21 de outubro de 1966. Autoriza o poder executivo a instituir a Fundação Universidade do Maranhão e dá outras providências. Coleção de Leis da República. v.7, p.279281, out./dez. 1966. Brasília: Imprensa Nacional, 1966.

BRASIL. Lei $n^{\circ} 5692$, de 11 de agosto de 1971. Fixa Diretrizes e Bases para o ensino de $1^{\circ}$ e $2^{\circ}$ graus, e dá outras providências. Coleção de Leis da República. v.5, p.59-68, jul./set. 1971. Brasília: Imprensa Nacional, 1971.

BRASIL. Lei $n^{\circ}$ 7044, de 18 de outubro de 1982. Altera dispositivos da Lei 5.692, de 11 de agosto de 1971, referentes a profissionalização do ensino de $2^{\circ}$ grau. Coleção de Leis da República. v.7, p.75-79, out./dez. 1982. Brasília: Imprensa Nacional, 1982.

BRASIL. Lei n 9394, de 20 de dezembro de 1996. Estabelece as diretrizes e bases da educação nacional. Coleção das Leis da República Federativa do Brasil. v.188, n.12, t.2, p.6544-6579, dez. 1996. Brasília: Imprensa Nacional, 1996.

BRASIL. Ministério da Educação. Base Nacional Comum Curricular. Brasília, 2018.

Manifesto dos Pioneiros da Educação Nova [documento (1932)]. Revista Histedbr on-line, Campinas, n. especial, p.188-204, ago. 2006 - ISSN: 1676-2584. Disponível em: http://www.histedbr. fe.unicamp.br/revista/edicoes/22e/doc1_22e.pdf. Acesso em 11-01-2020. 


\section{Arquivo Escolar}

COLUN. Estrutura e funcionamento do Colégio Universitário, 1990.

COLUN. Reformulação da grade curricular de $1^{\circ}$ e $2^{\circ}$ graus, 1984.

COLUN. Regimento interno do Colégio Universitário, 1972.

COLUN. Regimento interno do Colégio Universitário, 1982.

COLUN. Relatório de atividades do Colégio Universitário, 1990.

COLUN. Relatório de atividades do Colégio Universitário, 1991.

Jornal

COLUN pede socorro. BOLETIM APRUMA INFORMA, São Luís, p.9, dezembro de 1999. 